\title{
SOROEPIDEMIOLOGIA RETROSPECTIVA DO HIV-1
}

\author{
R. ISHAK (1), M. O. G. ISHAK (1), K. TSIQUAYE (2) \& D. D. P. CARDOSO (3)
}

\begin{abstract}
RESUMO
Amostras de soro de grupos populacionais dos Estados do Pará e Goiás, coleta. dos entre 1974 e 1980. foram testadas (ELISA, imunofluorescência e immunoblot) para a presença de anticorpos contra o vírus da imunodeficiencia humana tipo-1 (HIV-1). O objetivo principal foi de se mapear epidemiologicamente a ocorrencia deste vírus em um período anterior a detecção da presente epidemia. Quatro amos. tras dos índios Xicrin foram positivas pelo teste de ELISA, porém não foram confir madas pelos demais testes. Os resultados negativos sugerem a ausencia de circulação do HIV-1, nos grupos testados. no período pré 1980.
\end{abstract}

UNITERMOS: Soroepidemiologia: HIV: SIDA AIDS

\section{INTRODUÇĀO}

Ao início da década de 1980, com o surgi mento de casos de uma nova entidade clínica. a sindrome de Imunodeficiência Adquirida (SIDA AIDS , e a posterior correlaçāo etiológica desta sindrome com a descrição de um novo agente viral da família Retroviridae, o virus da imunodeficiência humana (HIV), têm-se procu rado extensivamente uma ponte epidemiologica que explique o aparecimento do agente. e sua instalaçāo com sucesso, no homem.

É nossa finalidade no presente trabalho, mostrar um segmento de evidencia experimen tal a respeito da origem da SIDA AIDS no Brasil, traçando-se a presença de anticorpos contra o HIV antes do alarme epiclêmico da década de 80. Nesta tentativa de se mapear indiretamente pela via soroepidemiológica a circulaçāo do ví. rus em um periodo anterior a detecçāo da pre sente epidemia, foram escolhidas coleçoes espe cificas de soro que continham informaçoes prévias para patógenos virais, ou não, e que haviam sido coletadas durante a década de 70 .

\section{MATERIAIS E MÉTODOS}

\section{Grupos Populacionais Testados e suas Características}

Um total de 640 amostras de soro de diferen tes grupos populacionais dos Estados do Pará e Goiás, coletadas entre 1974 e 1980, foram sele cionadas para o presente trabalho. Todas as amostras estavam estocadas a $-20^{\circ} \mathrm{C}$ e serviram para outros projetos de pesquisa ou para triagem de agentes transmitidos pelo sangue ou foram

\footnotetext{
(1) Universidade Federal do Pará. Centro de Ciencias Biologicas. Departamento de Patologia. Laboratorio de Vjrologia. Belém Para, Brasil.

(2) London School of Hygiene and Tropical Medicine. Londres. Inglaterra

(3) Instituto de Patologia Tropical e Saude Publica. Universidade Federal de Goiás. Goiania. Goiás, Brasil

Endereço para correspondencia: Dr. Ricardo Ishak. Caixa Postal 3005. CEP 66000. Belem, Pará, Brasil.
} 
ISHAK, R: ISHAK, M. O. G.: TSIQUAYE, K. \& CARDOSO, D. D. P. - Soroepidemiologia retrospectiva do HIV 1. Rev. Inst. Med. trop. Sāo Paulo, 31 (2): 80-83, 1989.

coletados para a rotina de diagnóstico de viroses.

Os grupos populacionais testados possuiam as características seguintes:

(i) comunidades consideradas de maior risco para a transmissão sexual do HIV

- 83 homossexuais e prostitutas da cidade de Goiânia-GO, que haviam mostrado prevalência de $7,2 \%$ (CARDOSO,D.D.P. e ISHAK, R., dados não publicados) do antígeno de superfície do vírus da hepatite $B$ (HBsAg), um agente viral que é largamente transmitido pela via sexual em de terminadas situaçỏes ${ }^{4.8}$;

- 84 indivíduos da populaçāo geral de Serra Norte - PA, os quais apresentaram um alto índice de exposiçāo $(76,2 \%)$ à Chlamydia trachomatis ${ }^{5}$. bactéria transmitida largamente pela via se xual; a possível persistência da $\mathbf{C}$. trachomatis neste grupo também foi alta $(43 \%)$, sugerindo que nestes dois grupos a via sexual é de extrema importância para a manutenção destes patóge nos.

(ii) comunidades urbanas em geral, de Belém-PA - 300 doadores voluntários de sangue que mos traram prevalència de HBsAg baixa $(1,8 \%)$, com pativeis com os niveis urbanos encontrados em nosso país (ISHAK, $R$. dados nāo publicados):

- 97 indivíduos da população em geral que apresentaram exposição à C. trachomatis $(53,6 \%)$ em niveis médios e similares a comunidades urbanas ${ }^{5}$.

(iii) comunidade nāo-urbana epidemiologicamente fechada

- 76 índios da tribo dos Xicrin ao sul do Estado do Pará que evidenciaram um nivel de preva lência de anticorpos para C. trachomatis $(51,3 \%)$ semelhante ao encontrado em várias comuni dades urbanas ${ }^{5}$.

\section{Testes Utilizados}

As amostras de soro foram testadas para a presença de anticorpos para o HIV-1 através de metodologias padrāo tais como:

(i) Ensaio imunoenzimático (ELISA) - usou-se o kit produzido pelo laboratório Burroughs Wellcome que é um teste de competição em que sảo adicionados simultaneamente o soro teste e um soro positivo padrāo (conjugado a uma en zima) que vão se ligar ao antigeno; no caso do soro teste ser positivo há uma reaçào colorimétrica inversamente proporcional de acordo com a quantidade de anticorpos presence: a interpretação quantitativa obedeceu as indicaçóes con tidas no manual do fabricante:

(ii) Imunofluorescência indireta - foram utiliza das láminas com esfregaços de linfócitos infecta dos (linhagem celular $\mathrm{H} 9$ ) e linfócitos controle nāo-infectados como substrato para a reação: usou-se sempre o conjugado anti-imunoglobu lina total marcado com isotiocianato de fluores ceina:

(iii) Immunoblot (Western blot) - os soros positi vos pelo teste de ELISA foram testados por um teste padráo em que as tiras de nitrocelulose com proteinas virais foram preparadas no labo ratório de Virologia da London School of Hygiene and Tropical Medicine, Inglaterra.

Tanto a imunofluorescencia como o immu noblot são técnicas usadas rotineiramente que possuem um potencial diagnóstico largamente difundidos ${ }^{3 \cdot 9}$.

\section{RESULTADOS}

Dentre as 640 amostras testadas, apenas quatro, provenientes da comunidade dos índios Xicrin, mostraram alguma reaçāo positiva pelo teste de ELISA. Duas amostras ficaram ligeira mente acima do "cut off" do teste e duas foram francamente positivas.

Por ocasião dos testes confirmatórios (Imu nofluorescência e Immunoblot) todas as quatro amostras mostraram ser negativas.

\section{DISCUSSÃO}

A ausência de anticorpos para o HIV nos grupos populacionais testados reforça a hipóte se de que este vírus não estaria circulando em nosso País antes da década de 80 .

Devido as características peculiares de al guns dos grupos estudados tais como os homos sexuais, as prostitutas e os individuos de Serra Norte, onde mostrou-se evidéncia de transmissāo por via sexual de outros patógenos, pode-se também descartar a idéia de que o vírus pudesse estar presente, porém sem que se fizesse o seu correto diagnóstico. Sendo a via sexual a forma de disseminaçāo deste agente, seria de se esperar a presença do HIV nestes grupos considerados 
ISHAK, R.; ISHAK, M. O. G.; TSIQUAYE, K. \& CARDOSO, D. D. P. - Soroepidemiologia retrospectiva do HIV 1.

Rev. Inst. Med. trop. São Paulo, 31 (2): 80-83, 1989.

como sendo de maior potencial epidemiológico de transmissāo.

As reaçōes encontradas pelo teste imunoenzimático nas quatro amostras dos índios Xicrin, foram consideradas como reaçōes falso-positivas originadas, primariamente, em virtude da alta sensibilidade do teste, o qual, consequentemente, perde um pouco de sua especificidade

Os trabalhos de cunho soroepidemiológico que tem procurado a origem da SIDA/AIDS, até o presente, tem mostrado resultados contraditórios ${ }^{1,2,6,7,10,11,12,13,14,15,16}$ e sofrem a interferência de fatores que incluem o método sorológico escolhido, o estado de conservação da amostra testada, a presença de anticorpos em títulos elevados para outras infecções e a reação cruzada com outros retrovírus e antígenos celulares.

\section{SUMMARY}

\section{HIV-1 RETROSPECTIVE SEROEPIDEMIOLOGY}

Serum samples collected between 1974 and 1980 out of populations from the States of Pará and Goiás, Brazil, were tested for antibodies against HIV-1 through ELISA, immunofluores cence, and immunoblot. The aim was to describe the possibility of the virus presence in this coun try before the present epidemic. Four samples from an epidemiologically closed community, the $\mathrm{Xicrin}$ indians, gave positive reaction in the ELISA test, but were negative in the confirma tory tests. The negative results suggest the absence of HIV-1, in the groups tested, prior to the 1980's.

\section{AGRADECIMENTOS}

À CAPES, Brasil, ao Overseas Research Scheme, Inglaterra, e à Universidade Federal do Pará, pelo suporte financeiro ao presente traba lho. À Sra. FATIMA MON'TEIRO pela paciente datilografia do manuscrito.

\section{REFERÊNCIAS BIBLIOGRÁFICAS}

1. BIGGAR, R. J ; JOHNSON, B. K.; OSTER, C.; SARIN P. S.; OCHENG, D.; TUKEI, P.; NSANZE, H.; ALEXAN DER, S.; BODNER, A. J. \& SIONGOK, T, A - Regional variation in prevalence of antibody against human T-lymphotropic virus types $I$ and III in Kenya, East A frica. Int. J. Cancer, 35: 763-767, 1985

2. BIGGAR, R. J ; MELBYE, M ; KESTENS. L ; FEYTER, M.; SAXINGER, C.; BODNEK, A. J ; PALUKO, L.; BLATTNER, W. A. \& GIGASE, P. L. - Seroepidemiology of HTLV.III antibodies in a remote population in eastern Zaire. Brit. med. J., 290: 808-810, 1985

3. CAstro, B. G.; CAstilho, E. A. \& PEREIRA, H. G - AIDS: Sindrome de imunodeficiencia adquirida. Ciència Hoje, 5: 26-37, 1986

4. HOOP, D.; ANKER, W. J. J ; van STRIK, R.; MASUREL N. \& STOLZ, E. - Hepatitis B antigen and antibody in the blood of prostitutes visiting an outpatient venereology department in Rotterdam. Brit. J. vener. Dis., 60: 319 -322, 1984

5. ISHAK, M. O.G.; MUMTAZ, G.; ISHAK, R. \& RIDGWAY, G. - Prevalência de anticorpos para Chlamydia trachomatis em grupos populacionais do Brasil, Inglaterra e Por. tugal. Kev. Inst. Med. trop. S. Paulo, 30: 40-44, 1988.

6. LEVY, J. A.; PAN, L. Z; BETH-GIRALDO, E ; KAMINS KY, L. S.; HENLE, G.; HENLE, W. \& GIRALDO, C. Absence of antibodies to the human immunodeficiency virus in sera from Africa prior to 1975. Proc. nat. Acad Sci. (Wash), 83: 7935-7937, 1986

7. LYONS, S. F; SCHOUB, B. D; MCGILLIVRAY, G. M; SHER, R \& SANTOS, L. - Lack of evidence of HTLV III endemicity in southern Africa. New Engl. J. Med., 312: $1257 \cdot 1258,1985$.

8. MIKHAILOV, $\mathrm{P}$ - TONEV $\mathrm{S}$ \& PRAMATOROV $\mathrm{K}$ Comparative studies on hetero- and homossexual men about frequency of hepatits-A, hepatitis-B and cytomegalovirus infections. Europ. J. sex. transm. Dis., 3: 51-52, 1985

9. MORTIMER, B.; PARRY, J. V. \& MORTIMER, J. Y. Which anti HTLV-III/LAV assays for screening and confirmatory testing? Lancet, 2: $873-877,1985$

10. NAHMIAS, A. J.; WEISS, J ; YAO, X; LEE, F ; KODSI R.: SCHANFIELD, M.; MATHEWS, T.;BOLOGNESI, D. DURACK, D.; MOTULSKY, A.: KANKI, P. \& ESSEX, M. - Evidence for human infection with an HTLV-III/LAV - like virus in central Africa, 1959. Lancet, 1: 1279-1280, 1986 .

11. QUINN, T. C: MANN, J. M.; CURRAN, J. W. \& PIOT P. - AIDS in Africa: an epidemiologic paradigm. Science, 234: $955-963,1986$

12. ROSENIOR, J. - Origin of AIDS. Nature, 318: 1985.

13. SAXINGER, W. C.; LEVINE, P. H. DEAN, A G.; de THE G.; LAVE-WANTZIN, C.; MOGHISSI, J ; LAURENT, F ; HOH, M.; SARNGADHARAN, M. G. \& GALLO, R. C. Evidence for exposure to HTLV-III in Uganda before 1973 Science, 227: 1036-1038, 1985

14. SHER, R.; ANTUNES, S.; REID, B. \& FALCKE, H. Seroepidemiology of human immunodeficiency virus in 
ISHAK, R.; ISHAK, M. O. G.; TSIQUAYE, K. \& CARDOSO, D. D. P. - Soroepidemiologia retrospectiva do HIV -1. Rev. Inst. Med. trop. São Paulo, 31 (2): 80-83, 1989.

Africa from 1970 to 1974 . New Engl. J. Med., 317: 450-451, 16. 1987.

15. WENDLER, I.; SCHNEIDER, J.; GRAS, B.; FLEMING, A. F.; HUNSMANN, G. \& SCHMITZ, H. - Seroepidemio logy of human immunodeficiency virus in Africa. Brit. med. J., 293: 782-785, 1986 :
WONG-STAAL, F. \& GALLO, R. C. - Human T.lympho tropic retroviruses. Nature, $317: 395-403,1985$

Recebido para publicação em 24/8/1988 